\title{
Características tecnológicas do caldo de variedades de cana-de-açúcar cultivadas em solo de cerrado com diferentes níveis de adubação fosfatada
}

\section{Technological characteristics of sugarcane varieties juice cultivated under savannah soil with different rate of phosphorus fertilizer}

\author{
Edson Belisario TEIXEIRA ${ }^{1,2}$; Antonio Cesar BOLONHEZI ${ }^{3}$; Francisco Maximino FERNANDES ${ }^{3}$; \\ Nelcinei Antonio RIBEIRO4; Cleiton José QUEIROZ ${ }^{5}$ \\ ${ }^{1}$ Parte da dissertação de mestrado do primeiro autor. \\ 2 Engenheiro Agrônomo; UNESP - Campus de Ilha Solteira; edimteixeira@hotmail.com \\ 3 Professor Assistente Doutor; UNESP - Campus de Ilha Solteira; bolonha@agr.feis.unesp.br \\ 3 Professor Adjunto; UNESP - Campus de Ilha Solteira; maximino@agr.feis.unesp.br \\ ${ }^{4}$ Engenheiro Agrônomo; Alcoolvale Açúcar e Álcool S/A; nelcinei.ribeiro@alcoolvale.com.br \\ ${ }^{5}$ Graduando em Agronomia; UNICASTELO - Campus de Fernandópolis; Cleiton.queiroz@alcoolvale.com.br
}

Recebido em: 17-07-2014; Aceito em: 12-08-2015

\begin{abstract}
Resumo
No Brasil, a área cultivada com cana-de-açúcar expandiu-se para solos de cerrado, que são caracterizados por baixa fertilidade, principalmente em conteúdo de fósforo; consequentemente, o crescimento da planta é reduzido nestas condições ambientais restritas. $O$ objetivo desta pesquisa foi estudar, na primeira soqueira de 10 variedades de cana-de-açúcar, os efeitos de dois níveis de adubação fosfatada (150 e $300 \mathrm{~kg} \mathrm{ha}^{-1}$ de $\mathrm{P}_{2} \mathrm{O}_{5}$ ) sobre características tecnológicas, tais como: Brix\%, Pol\% caldo, Fibra\% e o ATR $\mathrm{kg} \mathrm{t}^{-1}$ de cana. O experimento foi conduzido em ambiente de produção $D$ e solo classificado como Latossolo Vermelho álico, situado na Usina Alcoolvale em Aparecida do Taboado-MS. A fonte de fertilizante fosfatado foi o superfosfato simples, a aplicação foi realizada antes do plantio, e a incorporação foi feita através de gradagens. Amostras de 10 colmos foram colhidas em quatro diferentes datas ( 20 de maio, 20 de junho, 20 de julho e 20 de agosto de 2006) e submetidas a análises tecnológicas realizadas no Laboratório da Usina Alcoolvale, conforme método-padrão CONSECANA. Foram observadas diferenças entre as variedades quanto ao nível de fertilizante fosfatado aplicado. Na primeira

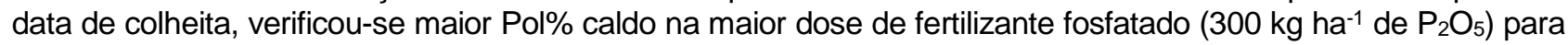
variedades de início e final de safra. Conclui-se que a adubação fosfatada é uma importante estratégia no planejamento da qualidade da matéria-prima e deve ser levado em conta para melhorar os resultados agronômicos de canaviais em condições do cerrado brasileiro.
\end{abstract}

Palavras-chave adicionais: adubação; época de corte; fósforo; sacarose; Saccahrum spp.

\begin{abstract}
In Brazil, sugarcane crop expanded in terms of acreage to the Brazilian Savannah soils which are characterized by low chemical fertility mainly phosphorus content, consequently the plant growth is reduced in this restrict environmental conditions. The objective of this research was to study at first ratoon of ten sugarcane varieties cultivated in two phosphorus rate $\left(150\right.$ and $300 \mathrm{~kg} \mathrm{ha}^{-1}$ of $\left.\mathrm{P}_{2} \mathrm{O}_{5}\right)$, the effects on the technological characteristics, such as: Brix\% juice, Pol\% juice, Fiber\% and ATR (recoverable total Sugar expressed by $\mathrm{kg} \mathrm{t}^{-1}$ of stalk). The trial was carried out in D class in terms of quality level soil, representing low yield potential, and soil classified as a Red Latosol alic (Oxisol) at Alcoolvale Sugar Mill situated in Aparecida do Taboado city, Mato Grosso do Sul State, Brazil. The phosphorus fertilizer used was superphosphate and the application was done before planting with incorporation by disking tillage. Samples of 10 stalks per plot were harvested in four different dates (May 20, June 20, July 20 and August 20 of 2006) and were submitted to analysis at Alcoolvale Sugar Mill laboratory using the CONSECANA pattern method. It was observed different responses among the sugarcane varieties with the increase of phosphorus rate. At the first harvest date, it could be quantified more Pol\% juice with phosphorus rate of $300 \mathrm{~kg} \mathrm{ha}^{-1}$ of $\mathrm{P}_{2} \mathrm{O}_{5}$ for early and late varieties. In conclusion, the phosphorus fertilization is an important strategy to manage the quality of raw material and must be take account to improve the results in Brazilian savannah environments.
\end{abstract}

Additional keywords: fertilization; harvest season; phosphorus; Saccahrum spp.; sucrose. 


\section{Introdução}

A crescente demanda pelos principais produtos da cadeia sucroenergética (açúcar e etanol) vem aquecendo o mercado mundial. Ótima oportunidade para o Brasil, pelo potencial de expansão agrícola e pelo grau de maturidade da agroindústria sucroalcooleira nacional.

Na safra de 2013/2014 no Brasil, foram produzidos 27,96 bilhões de litros de etanol e 37,88 miIhões de toneladas de açúcar (CONAB, 2014). O Ministério da Agricultura projetou que a produção de etanol deverá atingir 58,8 bilhões de litros em 2019 (MAPA, 2014), e a produção de açúcar, para o mesmo período, pode chegar a 50,9 milhões de toneladas (MAPA, 2013a). Para atender a esta demanda, além do aumento em área cultivada, é imprescindível elevar o ganho em produtividade.

Assim, a cultura vem destacando-se e expandindo-se na região do cerrado do Centro-Oeste brasileiro, principalmente em áreas antes ocupadas por pastagens degradadas. Deste modo, para viabilizar a cana-de-açúcar nestes ambientes, são necessárias adoções de tecnologias de manejo dos solos que priorizem a redução da erosão, proporcionem maior longevidade ao canavial e melhoria da condição química do solo em subsuperfície, já que são, em sua grande maioria, solos de textura arenosa e média, excessivamente drenados e de baixa fertilidade, caracterizando ambientes de produção denominados restritivos.

As práticas de manejo da fertilidade dos solos destas regiões, ao longo do tempo, passam pela adubação corretiva e de manutenção, e devem ser encaradas como investimento pela unidade agroindustrial.

Embora seja grande o número de trabalhos com adubação corretiva utilizando o fósforo em canade-açúcar (Morelli et al.,1991; Cantarella et al., 2002; Figueiredo Filho, 2002; Rosseto et al., 2002), deve-se considerar a influência do ambiente de produção sobre as variedades dentro do manejo varietal. O planejamento de variedades cultivadas em uma unidade industrial é de suma importância e fundamenta-se no conhecimento de suas características agronômicas, bem como em sua adaptabilidade às diversas situações ambientais. O potencial genético de cada variedade precisa ser avaliado, em cada local, em condições climáticas favoráveis e desfavoráveis, antes de seu cultivo em escala comercial (Lima et al., 1990).

De acordo com Malavolta (2006), o fósforo, sem dúvida, trata-se do nutriente que mais limita a produção vegetal no Brasil, e a elevação de sua disponibilidade, de forma a vencer a barreira imposta pela carência do solo por este nutriente, é um dos grandes desafios no manejo da fertilidade do solo. Os teores de fósforo nos solos da região do Cerrado são muito baixos. Essa característica, associada à alta capacidade que esses solos têm para reter o fósforo na fase sólida, é a principal limitação para o desenvolvimento de qualquer atividade agrícola rentável, sem a aplicação de adubos fosfatados (Sousa \& Lobato, 2004).

A aplicação do adubo fosfatado localizado no sulco de plantio possibilita maior relação fósforo por volume de solo, mas reduz a proporção de raízes que poderiam absorver os nutrientes. Enquanto a aplicação a lanço proporciona maior contato do fósforo com o solo, o que favorece sua adsorção (Sousa \& Volkweiss, 1987), mas propicia maior volume de solo a ser explorado pelas raízes em relação à adubação localizada (Sousa \& Lobato, 2004).

A aplicação de fosfato no sulco de plantio é a única oportunidade de colocar o fósforo próximo às raízes, necessitando da calibragem da dose, de modo a suprir os anos subsequentes, em vista da impossibilidade de aplicar o fósforo junto às raízes das socas e da baixa mobilidade deste nutriente no solo (Rossetto \& Dias, 2005).

A aplicação da dose adequada de fósforo em cana-planta é da maior importância para o estabelecimento de uma boa população de colmos, o que contribui para a obtenção de soqueiras em melhores condições de produtividade (Rodella \& Martins, 1988).

Sabe-se que, pelo fato de o fósforo ter efeito benéfico sobre o desenvolvimento das raízes, a planta irá explorar maior área de solo, e possivelmente estará mais bem nutrida, também tem a propriedade de aumentar a eficiência da utilização de água pela planta (Korndörfer, 2004), possibilitando, portanto, melhores condições para produzir mais sacarose.

Segundo Korndörfer et al. (1998), em solos onde se instala a cultura da cana-de-açúcar pela primeira vez, é grande a resposta da cana-planta à adubação fosfatada. $E$ ainda afirmam que, para solos distróficos ou com vegetação de cerrado, a dose de $120 \mathrm{~kg} \mathrm{ha}^{-1}$ de $\mathrm{P}_{2} \mathrm{O}_{5}$ é a que possibilita maior retorno econômico para o produtor, quando se considera a produção acumulada de cana-planta e primeira soca.

De acordo com Penatti (1991), a adubação fosfatada pode aumentar a produção de cana, no entanto o teor de sacarose da cana é pouco afetado, mas para Albuquerque et al. (1979), o fósforo aumentou o teor de sacarose da cana, enquanto outros trabalhos mostraram que não ocorreu resposta positiva à adubação fosfatada sobre características tecnológicas dessa cultura (Korndörfer, 1990; Pereira et al.,1995; Figueiredo Filho, 2002; Rossetto et al., 2002). Souza \& Korndörfer (2011) não observaram efeito de fontes e de doses de fósforo no rendimento agrícola e industrial quando trabalharam em um Latossolo Vermelho ácrico de textura argilosa, com as variedades SP71-1406 e RB867515.

Estudando solos muito pobres em fósforo, Sobral et al. (1994) relataram que os valores de sacarose nas plantas podem ser muito inferiores, comparado-se as plantas bem nutridas com o referido elemento. Isso porque o fósforo tem papel importante na formação de sacarose quando o composto glicose-1fosfato se junta à frutose para formar a sacarose. No entanto, Martins (2004) não confirmou esta hipótese, 
pois em solos com altos teores de fósforo não se verificou correlação entre os teores do elemento contido no solo e a qualidade tecnológica da cana, assim como Pereira et al. (1995) não observaram influência de níveis crescentes de fósforo no Pol\% da cana.

Outro aspecto importante diz respeito ao manejo das variedades de cana-de-açúcar, pois, na prática, sabe-se que há uma interação forte entre a variedade e o ambiente agrícola. É preciso, portanto, avaliar o desempenho de variedades nestes ambientes de cerrado a fim de verificar a possibilidade de haver diferenças quanto ao manejo químico destes solos. Neste sentido, o presente trabalho objetivou avaliar, na primeira soqueira, o efeito de duas doses de fósforo aplicado antes do plantio em área total, sobre as características tecnológicas do caldo de dez variedades de cana-de-açúcar, em quatro épocas de corte.

\section{Material e métodos}

O experimento foi conduzido em uma fazenda administrada pela Usina Alcoolvale do município de Aparecida do Taboado-MS. As coordenadas geográficas são $51^{\circ} 15^{\prime} 00^{\prime \prime}$ W e $20^{\circ} 12^{\prime} 57^{\prime \prime} \mathrm{S}$, e altitude aproximada de $374 \mathrm{~m}$.

Segundo a classificação internacional de Köppen, o clima da região é do tipo Aw, definido como tropical úmido, com estação chuvosa no verão e seca no inverno, apresentando temperatura e precipitação média anual de $23,5^{\circ} \mathrm{C}$ e $1.560 \mathrm{~mm}$, respectivamente.

O solo da área experimental foi classificado como Latossolo Vermelho álico (EMBRAPA, 2006), textura média argilosa entre 26 e $35 \%$ de argila, caracterizado como ambiente de produção "D". A análise química do solo, de 0,0 até $0,2 \mathrm{~m}$ de profundidade, revelou: $\mathrm{pH}\left(\mathrm{CaCl}_{2}\right)$ 4,0; $\mathrm{P}$ (resina) $1 \mathrm{mg} \mathrm{dm}{ }^{-3}$; M.O. $18 \mathrm{mg} \mathrm{dm}{ }^{-3} ; \mathrm{K}, \mathrm{Ca}, \mathrm{Mg}, \mathrm{Al}, \mathrm{SB}$ e CTC de 0,6; 4,0; 2,0;11,0;6,6 e 53,6 $\mathrm{mmol}_{\mathrm{c}} \mathrm{dm}^{-3}$, respectivamente, e $\mathrm{V} \%$ de 12,0 .

$\mathrm{O}$ delineamento experimental foi $\mathrm{o} \mathrm{em}$ blocos casualizados, com parcelas subsubdivididas, sendo dois níveis de fosfatagem corretiva, 150 e $300 \mathrm{~kg} \mathrm{ha}^{-1}$ de $\mathrm{P}_{2} \mathrm{O}_{5}$, nas parcelas principais, com dez variedades nas subparcelas: RB867515, RB855035, RB72454, RB835486, SP84-1431, SP83-2847, SP81-3250, SP79-1011, IACSP93-6006 e IAC91-5155, e quatro épocas de corte nas subsubparcelas.

Anteriormente à instalação do experimento, a área estava ocupada por pastagem em estado avançado de degradação; dessa forma, foram realizadas as operações de sistematização e preparo do solo com duas gradagens, com discos de 32 polegadas de diâmetro, para eliminar as plantas daninhas. Fez-se a calagem com calcário dolomítico (PRNT $87 \%$ ) na dose de 2,9 t ha $^{-1}$ para elevar a saturação por bases para $60 \%$, incorporando o corretivo com grade de discos de 28 polegadas de diâmetro. Em seguida, foi realizada a adubação corretiva com as doses de $\mathrm{P}_{2} \mathrm{O}_{5}$, e incorporação do superfosfato simples com grade de discos de 28 polegadas de diâmetro.

Em abril de 2004, foi realizado o plantio manual com mudas de 11-12 meses de idade, em sulcos de $0,35 \mathrm{~m}$ de profundidade, no espaçamento de $1,40 \mathrm{~m}$, sendo as parcelas compostas por cinco linhas de plantio com 10,0 m de comprimento. A adubação no sulco de plantio foi com $550 \mathrm{~kg} \mathrm{ha}^{-1}$ da fórmula 6-30-21, acrescida de $0,1 \%$ de B, $0,4 \%$ de $\mathrm{Cu}$ e $0,5 \%$ de $\mathrm{Zn}$. Na cobertura dos toletes, fez-se a aplicação de fipronil $800 \mathrm{~g} \mathrm{~kg}^{-1}$, na dose de 0,2 kg do i.a. por hectare. Após o corte da cana-planta, foi realizada a adubação da soqueira com $500 \mathrm{~kg} \mathrm{ha}^{-1}$ do adubo fórmula 18-6-24 aplicado superficialmente sobre a linha da cana, sem a movimentação do solo.

Nos dias 20 de maio, 20 de junho, 20 de julho e 20 de agosto de 2006, foram coletados 10 colmos de cada parcela experimental, seguidos nos níveis 150 e $300 \mathrm{~kg} \mathrm{ha}^{-1}$ de $\mathrm{P}_{2} \mathrm{O}_{5}$. As amostras de cana foram analisadas no laboratório da Usina Alcoolvale, conforme CONSECANA (2006).

A precipitação pluviométrica da área experimental, com início no corte da cana-planta em agosto de 2005, até à data da última época de corte do experimento, em agosto de 2006, pode ser observada na Figura 1.

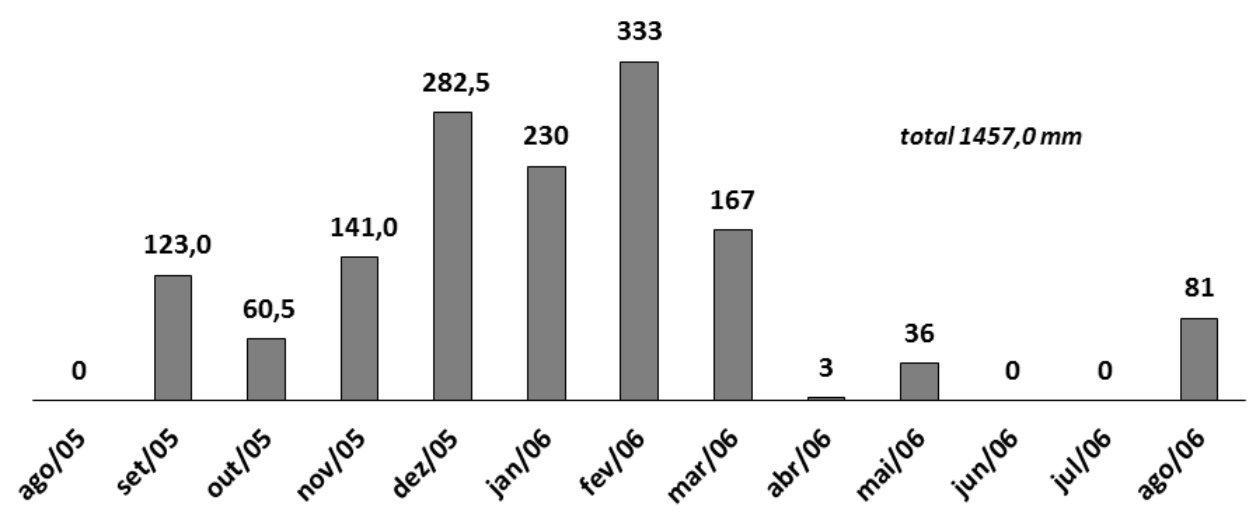

Figura 1 - Precipitação pluvial durante o período de avaliação do experimento, de agosto de 2005 a agosto de 2006. Rainfall ( $\mathrm{mm}$ ) during the evaluation of research, from August 2005 to August 2006. 
Os dados obtidos do teor de sólidos solúveis, em peso de caldo (Brix\%), teor de sacarose aparente por cento em peso de caldo (Pol\% caldo), Fibra\% e o açúcar total recuperável (ATR) calculado foram submetidos à análise de variância, pelo teste $\mathrm{F}$, e as médias, comparadas pelo teste de Scott Knott e regressão, a $5 \%$ de probabilidade. Utilizou-se o programa estatístico SISVAR (Ferreira, 2000).

\section{Resultados e discussão}

Analisando os dados da análise de variância, pode-se observar que o fator doses, independentemente da época de corte e das variedades, não apresentou significância para as características avaliadas (Tabela 1). Mesmo com algumas variedades possuindo desenvolvimento e ciclos de maturação semeIhantes, houve significância em todas as características avaliadas, evidenciando a grande variabilidade genética entre as variedades. Não houve resposta significativa para a interação entre doses e variedades, concordando com os resultados apresentados por Lima et al. (2006) e Korndörfer \& Melo (2009), em que os autores verificaram que a adubação mineral fosfatada não proporcionou efeito nas características tecnológicas da cana-de-açúcar nem entre níveis crescentes de doses de fósforo. Mas, para doses versus épocas e épocas versus variedades, as características Brix\%, Pol\% caldo e ATR $\mathrm{kg} \mathrm{t}^{-1}$ cana apresentaram alta significância. Na interação tripla entre doses versus épocas versus variedades, apenas para Brix\% e Fibra\%, não houve significância. Elamin et al. (2007) e Santos et al. (2011) também não observaram efeitos significativos da adubação fosfatada sobre o teor de fibra da cana-de-açúcar, mas em ambientes e variedades diferentes daquelas avaliadas nesta pesquisa.

Tabela 1 - Níveis mínimos de significância para as características Brix\%, Pol\% caldo, Fibra\% e ATR, na primeira soqueira, de dez variedades de cana-de-açúcar cultivadas sobre duas doses de $\mathrm{P}_{2} \mathrm{O}_{5}$, em fosfatagem corretiva e com quatro épocas de corte. Minimum levels of significance for the characteristics Brix\%, Pol\% juice, fiber\% and ATR (recoverable total Sugar expressed by $\mathrm{kg} \mathrm{t}^{1}$ of stalk), first ratoon of ten varieties of sugarcane grown under two rates of superphosphate, harvested in four different dates.

\begin{tabular}{|c|c|c|c|c|}
\hline \multirow{3}{*}{ Fonte de variação } & \multicolumn{4}{|c|}{ Características tecnológicas } \\
\hline & Brix\% & POL\% caldo & Fibra\% & ATR $\mathrm{kg} \mathrm{t}^{-1}$ cana \\
\hline & \multicolumn{4}{|c|}{$\operatorname{Pr}>\mathrm{Fc}^{1}$} \\
\hline Doses & 0,7779 & 0,2230 & 0,2502 & 0,3094 \\
\hline Variedades & 0,0001 & 0,0001 & 0,0001 & 0,0001 \\
\hline Doses*variedades & 0,6262 & 0,8264 & 0,4377 & 0,7291 \\
\hline Épocas de corte & 0,0001 & 0,0001 & 0,0001 & 0,0001 \\
\hline Doses*épocas & 0,0288 & 0,0001 & 0,0364 & 0,0004 \\
\hline Épocas*variedades & 0,0012 & 0,0012 & 0,0269 & 0,0001 \\
\hline Doses*épocas*variedades & 0,0634 & 0,0062 & 0,0737 & 0,0164 \\
\hline Coeficiente de Variação 1 - (\%) & 3,47 & 1,21 & 8,39 & 2,29 \\
\hline Coeficiente de Variação 2 - (\%) & 3,58 & 4,86 & 6,35 & 4,53 \\
\hline Coeficiente de Variação 3 - (\%) & 3,22 & 4,85 & 5,71 & 4,36 \\
\hline
\end{tabular}

${ }^{1}$ Valores de $\mathrm{Pr}>\mathrm{Fc}$ iguais ou menores que 0,05 indicam diferença significativa a $5 \%$ de probabilidade e valores menores que 0,01 indicam significância a $1 \%$ de probabilidade.

Para a variável época de corte, independentemente das doses e das variedades utilizadas, houve significância em todas as características com incrementos lineares no período avaliado (Figura 2). Este comportamento era esperado, já que, nas condições climáticas da região Sudeste do Brasil, a maturação fisiológica natural da cana-de-açúcar inicia-se nos meses de abril/maio; e o clímax, nos meses de agosto/setembro.

Verifica-se que, para Brix\%, a variedade SP832847 obteve menor valor; no entanto, ficou agrupada com as variedades RB72454, RB867515, IACSP936006 e a IAC91-5155, pelo teste de Scott Knott, diferindo significativamente das variedades SP79-1011, RB855035, SP84-1431 e da RB835486 (Tabela 2).

Para a característica Pol\% caldo, as varieda- des foram separadas em duas classes, pelo teste de Scott Knott: em um grupo ficaram as variedades IACSP93-6006, RB72454, RB867515 e a SP83-2847, com os menores valores; e em outro, as variedades SP79-1011, SP81-3250, RB855035, IAC91-5155, SP84-1431 e a RB835486, com os maiores valores de Pol\% caldo.

Para Fibra\%, o maior destaque foi a SP832847, que acumulou 12,99\%; a RB72454 e a IACSP93-6006 obtiveram os menores valores dentre as variedades estudadas, com apenas $11,02 \%$ e $11,06 \%$, respectivamente.

Em relação ao ATR $\mathrm{kg} \mathrm{t}^{-1}$ cana, a SP83-2847 teve o menor valor, com apenas $137,10 \mathrm{~kg} \mathrm{t}^{-1}$ cana, ou seja, $9,8 \%$ a menos que a RB835486, que obteve o maior valor de $150,58 \mathrm{~kg} \mathrm{t}^{-1}$ cana. As variedades 
RB867515 e a IACSP93-6006 também ficaram entre as que apresentaram menores valores de ATR. Horii (2004) considerou que as variedades de cana-deaçúcar, devido aos diferentes comportamentos de maturação, podem ser agrupadas em: precoces, quando apresentarem teor de POL acima de $13 \%$ no início de maio; médias, quando atingem a maturação em julho; e tardias, quando o pico de maturação ocorre a partir de agosto e setembro. Como a varie-
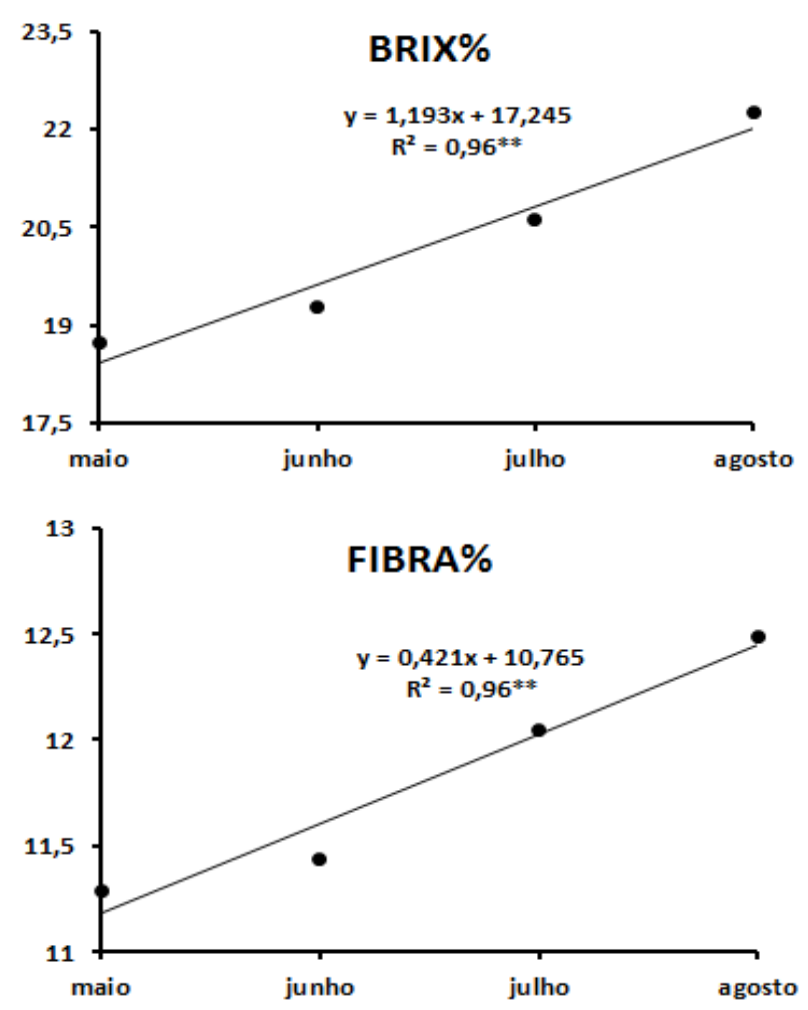

dade SP83-2847 possui características de maturação tardia, e as variedades RB867515 e IACSP93-6006 de maturação média a tardia (COPERSUCAR, 1999; IAC, 2000; RIDESA, 2008), é possível que, na última época de corte realizada em agosto, essas variedades não tenham expressado o total potencial para acumular sacarose.
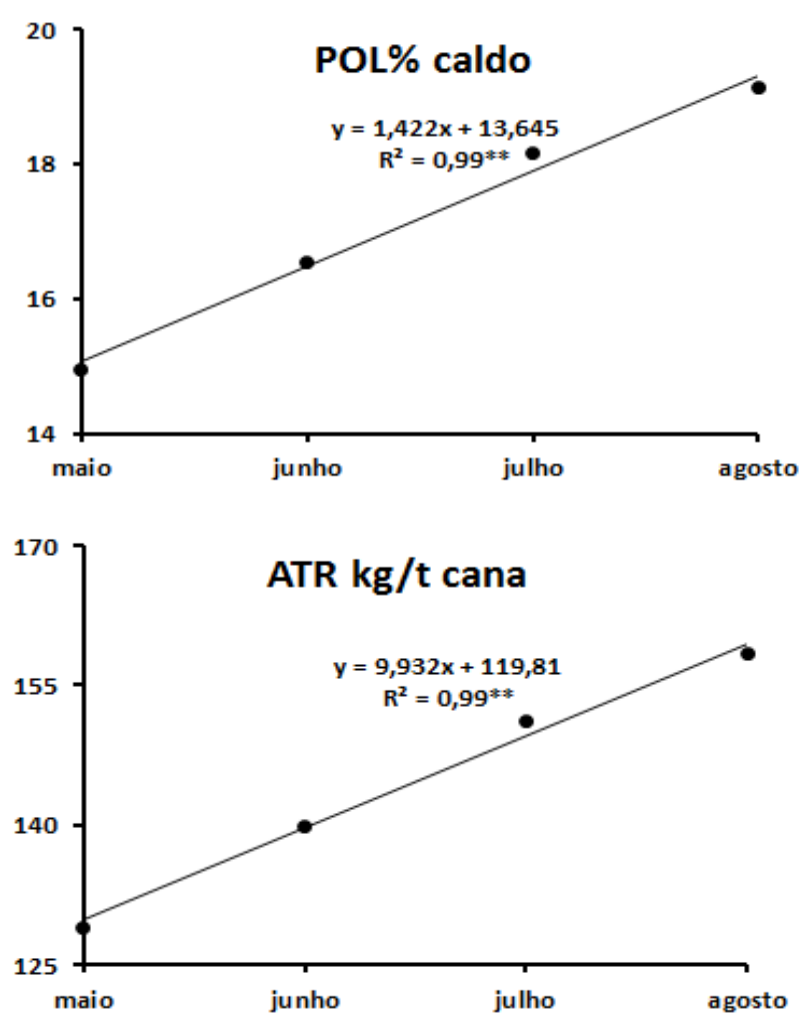

Figura 2 - Regressão para Brix\%, Pol\% caldo, Fibra\% e ATR kg t-1 cana, na primeira soqueira, de dez variedades de cana-de-açúcar, em quatro épocas de corte, no ano de 2006. Regression of Brix\%, Pol\% juice, Fiber\% and ATR (recoverable total Sugar expressed by $\mathrm{kg} \mathrm{t}^{1}$ of stalk), at first ratoon of ten varieties of sugarcane, harvested in four different dates, in 2006.

Tabela 2 - Média das características tecnológicas Brix\%, Pol\% caldo, Fibra\% e ATR kg t-1 cana, na primeira soqueira, de dez variedades de cana-de-açúcar. Average of technological characteristics Brix\%, Pol\% juice, fiber\% and ATR (recoverable total Sugar expressed by $\mathrm{kg} \mathrm{t}^{1}$ of stalk), at first ratoon of ten varieties of sugarcane.

\begin{tabular}{|c|c|c|c|c|}
\hline \multirow{2}{*}{ Variedades } & \multicolumn{4}{|c|}{${ }^{(*)}$ Características tecnológicas } \\
\hline & Brix\% & POL\% caldo & Fibra\% & ATR $\mathrm{kg} \mathrm{t}^{-1}$ cana \\
\hline SP83-2847 & $19,55 b$ & $16,60 \mathrm{~b}$ & $12,99 \mathrm{a}$ & $137,10 \mathrm{~d}$ \\
\hline RB72454 & $19,95 \mathrm{~b}$ & $16,86 \mathrm{~b}$ & 11,02 c & $144,04 \mathrm{~b}$ \\
\hline RB867515 & $19,91 \mathrm{~b}$ & $16,93 \mathrm{~b}$ & $11,85 \mathrm{~b}$ & $142,43 \mathrm{c}$ \\
\hline IACSP93-6006 & $19,77 b$ & $16,48 \mathrm{~b}$ & $11,06 \mathrm{c}$ & $140,61 \mathrm{c}$ \\
\hline SP79-1011 & $20,31 \mathrm{a}$ & $17,24 \mathrm{a}$ & $11,97 \mathrm{~b}$ & $144,57 b$ \\
\hline SP81-3250 & $20,61 \mathrm{a}$ & 17,32 a & $11,80 \mathrm{~b}$ & $145,92 \mathrm{~b}$ \\
\hline IAC91-5155 & $20,16 \mathrm{~b}$ & $17,56 \mathrm{a}$ & $11,81 \mathrm{~b}$ & $147,10 \mathrm{~b}$ \\
\hline RB855035 & $20,50 a$ & $17,35 \mathrm{a}$ & $12,16 \mathrm{~b}$ & $145,02 \mathrm{~b}$ \\
\hline SP84-1431 & $20,76 \mathrm{a}$ & $17,68 \mathrm{a}$ & $11,69 \mathrm{~b}$ & $148,95 \mathrm{a}$ \\
\hline RB835486 & $20,75 a$ & $17,97 \mathrm{a}$ & $11,79 b$ & $150,58 \mathrm{a}$ \\
\hline
\end{tabular}

${ }^{(*)}$ Médias seguidas de letras iguais nas colunas, não diferem entre si, a 5\% de probabilidade, pelo teste de Scott Knott. 
As doses de $\mathrm{P}_{2} \mathrm{O}_{5}$ em adubação corretiva não influenciaram sobre os teores de Brix\%, Pol\% caldo, Fibra\% e do ATR $\mathrm{kg} \mathrm{t}^{-1}$ cana (Tabela 3). Figueiredo Filho (2002) e Rossetto et al. (2002) também não observaram influência da adubação fosfatada nas características tecnológicas da cana-de-açúcar. Tomaz (2009) também não constatou o efeito de fontes, doses e formas de aplicação de fósforo nas qualidades da cana.

Tabela 3 - Média das características tecnológicas Brix\%, Pol\% caldo, Fibra\% e ATR $\mathrm{kg} \mathrm{t}^{-1}$ cana, na primeira soqueira, cultivada sob duas doses de $\mathrm{P}_{2} \mathrm{O}_{5} \mathrm{em}$ fosfatagem corretiva. Average of technological characteristics Brix\%, Pol\% juice, fiber\% and ATR (recoverable total sugar expressed by $\mathrm{kg} \mathrm{t}^{1}$ of stalk), at first ratoon grown under two rates of superphosphate.

\begin{tabular}{ccccc}
\hline $\mathrm{P}_{2} \mathrm{O}_{5}$ & \multicolumn{4}{c}{ Características tecnológicas } \\
\cline { 2 - 5 }$\left(\mathrm{kg} \mathrm{ha}^{-1}\right)$ & Brix\% & POL\% caldo & Fibra\% & ATR kg t $^{-1}$ cana \\
\hline 150 & 20,21 & 17,29 & 11,92 & 144,92 \\
300 & 20,24 & 17,10 & 11,71 & 144,34 \\
\hline
\end{tabular}

Ao se desdobrar os dados de doses dentro das épocas (Tabela 4), verifica-se que a primeira época de corte, realizada em maio, na dose de $300 \mathrm{~kg}$ ha ${ }^{-1}$ de $\mathrm{P}_{2} \mathrm{O}_{5}$, as médias de Pol\% caldo e ATR foram significativamente maiores, não havendo diferença entre as características na segunda época de corte, no mês de junho. Já em julho, os dados revelam médias de Brix\%, Pol\% caldo, Fibra\% e ATR maiores na dose de $150 \mathrm{~kg} \mathrm{ha}^{-1}$ de $\mathrm{P}_{2} \mathrm{O}_{5}$, e, na quarta época, em agosto, as médias das duas doses de fósforo, como ocorreu em junho, foram estatisticamente iguais. $O$ fósforo tem papel importante na formação de sacarose quando o composto glicose-1-fosfato se junta à frutose para formar a sacarose (Alexander, 1973); sendo assim, do primeiro corte em agosto de 2005 até a primeira avaliação da época de corte em maio de 2006, praticamente não houve restrição hídrica (Figura 1).
Deste modo, a maior dose (300 kg ha-1) pode ter disponibilizado mais fósforo solúvel para a formação de sacarose. Por outro lado, nos cortes seguintes, como ocorreu restrição hídrica durante o período, a falta de água no solo, juntamente com a queda da temperatura por conta do inverno foram condições de estresse que favoreceram a maturação (Rodrigues, 1995), e os efeitos esperados para a maior dose não se confirmaram.

Vale salientar que, neste caso, o resultado é composto pela média de dez variedades com características distintas de desenvolvimento e maturação. Lima et al. (1990) citam que antes de se fazer uma recomendação de cultivo de uma variedade, o potencial genético precisa ser avaliado, em cada local, em condições climáticas favoráveis e desfavoráveis.

Tabela 4 - Média das características tecnológicas Brix\%, Pol\% caldo, Fibra\% e ATR $\mathrm{kg} \mathrm{t}^{-1}$ cana, na primeira soqueira, em quatro épocas de corte, cultivadas sob duas doses de $\mathrm{P}_{2} \mathrm{O}_{5}$ em fosfatagem corretiva. Average of technological characteristics Brix\%, Pol\% juice, fiber\% and ATR (recoverable total Sugar expressed by $\mathrm{kg} \mathrm{t}^{1}$ of stalk), at first ratoon harvested in four different dates grown under two rates of superphosphate.

\begin{tabular}{|c|c|c|c|c|c|c|c|c|}
\hline \multirow{3}{*}{ Época } & \multicolumn{8}{|c|}{$\mathrm{P}_{2} \mathrm{O}_{5}\left(\mathrm{~kg} \mathrm{ha}^{-1}\right)$} \\
\hline & \multicolumn{2}{|c|}{ (1)Brix\% } & \multicolumn{2}{|c|}{ (1)POL\% caldo } & \multicolumn{2}{|c|}{ (1)Fibra\% } & \multicolumn{2}{|c|}{ (1)ATR kg t ${ }^{-1}$ cana } \\
\hline & 150 & 300 & 150 & 300 & 150 & 300 & 150 & 300 \\
\hline Maio & $18,62 \mathrm{~A}$ & $18,83 \mathrm{~A}$ & $14,67 \mathrm{~B}$ & $15,23 \mathrm{~A}$ & $11,45 \mathrm{~A}$ & $11,12 \mathrm{~A}$ & $126,76 \mathrm{~B}$ & $131,37 \mathrm{~A}$ \\
\hline Junho & $19,31 \mathrm{~A}$ & $19,27 \mathrm{~A}$ & $16,71 \mathrm{~A}$ & $16,35 \mathrm{~A}$ & $11,32 \mathrm{~A}$ & $11,55 \mathrm{~A}$ & $141,18 \mathrm{~A}$ & $138,53 \mathrm{~A}$ \\
\hline Julho & $20,81 \mathrm{~A}$ & $20,44 \mathrm{~B}$ & $18,60 \mathrm{~A}$ & $17,75 \mathrm{~B}$ & $12,27 \mathrm{~A}$ & $11,83 \mathrm{~B}$ & $153,70 \mathrm{~A}$ & 148,77 B \\
\hline Agosto & $22,11 \mathrm{~A}$ & $22,41 \mathrm{~A}$ & $19,17 \mathrm{~A}$ & $19,11 \mathrm{~A}$ & $12,62 \mathrm{~A}$ & $12,34 \mathrm{~A}$ & $158,04 \mathrm{~A}$ & $158,71 \mathrm{~A}$ \\
\hline
\end{tabular}

(1) Médias seguidas de letras iguais nas linhas, para a mesma característica, não diferem entre si, a $5 \%$ de probabilidade, pelo teste de Scott Knott.

De modo geral, para Brix\%, Pol\% caldo e ATR $\mathrm{kg} \mathrm{t}^{-1}$ cana, a regressão linear teve um ótimo ajuste para as variedades, confirmando que a qualidade da cana-de-açúcar começa ruim no início da safra e atinge o ponto mais alto na metade do período de safra (Tabelas 5; 6; 7 e 8).

Algumas variedades mostraram-se mais responsivas ao tratamento com doses mais elevadas de $\mathrm{P}_{2} \mathrm{O}_{5}$ em adubação corretiva, e ainda assim, essa resposta torna-se dependente da época de corte, da umidade no solo e da temperatura. É o caso da variedade IACSP93-6006, que na terceira época de corte (julho), a dose de $150 \mathrm{~kg} \mathrm{ha}^{-1}$ de $\mathrm{P}_{2} \mathrm{O}_{5}$ em adubação corretiva, foi superior à dose de $300 \mathrm{~kg} \mathrm{ha}^{-1}$ para Brix\%, Pol\% caldo e ATR $\mathrm{kg} \mathrm{t}^{-1}$ cana. Já na última época de corte, a maior dose foi a que proporcionou maior acúmulo para as mesmas características. $\mathrm{Na}$ variedade SP83-2847, apenas na última época, para a característica Brix\%, houve diferença significativa para a maior dose de fósforo. Já a variedade RB72454 mostrou-se menos responsiva à dose mais alta de fósforo, apresentando para Pol\% caldo e ATR maiores valores na dose $150 \mathrm{~kg} \mathrm{ha}^{-1}$. 
Tabela 5 - Característica Brix\%, na primeira soqueira, de dez variedades de cana-de-açúcar cultivadas sob duas doses de $\mathrm{P}_{2} \mathrm{O}_{5}$ em fosfatagem corretiva e com quatro épocas de corte. Characteristic Brix\%, first ratoon of ten varieties of sugarcane, grown under two rates of superphosphate, harvested in four different dates.

\begin{tabular}{|c|c|c|c|c|c|c|}
\hline \multirow{2}{*}{$\begin{array}{c}\text { Dose } \\
\left(\mathrm{kg} \mathrm{ha}^{-1}\right)\end{array}$} & \multirow{2}{*}{ Variedade } & \multicolumn{4}{|c|}{ (1)Épocas de corte } & \multirow{2}{*}{$\begin{array}{l}\text { Regressão } \\
\text { época }\end{array}$} \\
\hline & & Maio & Junho & Julho & Agosto & \\
\hline 150 & \multirow{2}{*}{ SP83-2847 } & $17,73 \mathrm{a}$ & $18,67 \mathrm{a}$ & $19,73 \mathrm{a}$ & $21,43 b$ & $r^{2} 97,87 \% *$ \\
\hline 300 & & $18,13 \mathrm{a}$ & $18,77 \mathrm{a}$ & $19,13 \mathrm{a}$ & $22,77 \mathrm{a}$ & $r^{2} 77,98 \% *$ \\
\hline 150 & \multirow{2}{*}{ RB72454 } & $18,13 \mathrm{a}$ & $19,37 \mathrm{a}$ & $20,40 \mathrm{a}$ & $22,07 \mathrm{a}$ & $r^{2} 99,02 \% *$ \\
\hline 300 & & $18,40 \mathrm{a}$ & $18,90 \mathrm{a}$ & $19,63 \mathrm{a}$ & $22,67 \mathrm{a}$ & $r^{2} 83,44 \% *$ \\
\hline 150 & \multirow{2}{*}{ RB867515 } & $18,10 \mathrm{a}$ & $18,93 \mathrm{a}$ & $20,30 \mathrm{a}$ & $22,03 \mathrm{a}$ & $r^{2} 97,70 \% *$ \\
\hline 300 & & $18,33 \mathrm{a}$ & $19,00 \mathrm{a}$ & $20,17 \mathrm{a}$ & $22,40 a$ & $r^{2} 93,42 \% *$ \\
\hline 150 & \multirow{2}{*}{ IACSP93-6006 } & $18,30 \mathrm{a}$ & $18,10 \mathrm{a}$ & $21,07 \mathrm{a}$ & $21,27 b$ & $r^{2} 79,64 \% *$ \\
\hline 300 & & $18,57 \mathrm{a}$ & $18,37 \mathrm{a}$ & $19,90 \mathrm{~b}$ & $22,57 \mathrm{a}$ & $r^{2} 81,55 \% *$ \\
\hline 150 & \multirow{2}{*}{ SP79-1011 } & $18,93 \mathrm{a}$ & $19,37 \mathrm{a}$ & $21,23 \mathrm{a}$ & $22,20 \mathrm{a}$ & $r^{2} 95,20 \% *$ \\
\hline 300 & & $18,63 \mathrm{a}$ & $19,33 \mathrm{a}$ & $20,37 \mathrm{a}$ & $22,40 \mathrm{a}$ & $r^{2} 94,22 \% *$ \\
\hline 150 & \multirow{2}{*}{ SP81-3250 } & $19,37 \mathrm{a}$ & $20,03 a$ & $20,70 \mathrm{a}$ & $22,23 \mathrm{a}$ & $r^{2} 95,01 \% *$ \\
\hline 300 & & $18,97 \mathrm{a}$ & $19,43 a$ & $21,07 \mathrm{a}$ & $23,10 \mathrm{a}$ & $r^{2} 93,87 \% *$ \\
\hline 150 & \multirow{2}{*}{ IAC91-5155 } & $18,47 \mathrm{a}$ & $19,10 \mathrm{a}$ & $20,83 a$ & $21,90 \mathrm{a}$ & $r^{2} 97,27 \% *$ \\
\hline 300 & & $18,83 a$ & $19,83 a$ & $20,33 a$ & $21,97 \mathrm{a}$ & $r^{2} 95,45 \% *$ \\
\hline 150 & \multirow{2}{*}{ RB855035 } & $18,90 \mathrm{a}$ & $19,40 \mathrm{a}$ & $21,27 \mathrm{a}$ & $22,80 \mathrm{a}$ & $r^{2} 95,72 \% *$ \\
\hline 300 & & $18,87 \mathrm{a}$ & $18,73 \mathrm{a}$ & $20,80 \mathrm{a}$ & $23,20 \mathrm{a}$ & $r^{2} 86,45 \% *$ \\
\hline 150 & \multirow{2}{*}{ SP84-1431 } & $19,20 \mathrm{a}$ & $20,80 \mathrm{a}$ & $20,70 \mathrm{a}$ & $22,97 \mathrm{a}$ & $r^{2} 86,99 \%$ * \\
\hline 300 & & $19,43 a$ & $19,97 \mathrm{a}$ & $21,20 \mathrm{a}$ & $21,80 \mathrm{~b}$ & $r^{2} 97,47 \% *$ \\
\hline 150 & \multirow{2}{*}{ RB835486 } & $19,03 \mathrm{~b}$ & $19,33 \mathrm{a}$ & $21,87 \mathrm{a}$ & $22,17 \mathrm{a}$ & $r^{2} 87,71 \% *$ \\
\hline 300 & & $20,20 \mathrm{a}$ & $20,37 a$ & $21,83 \mathrm{a}$ & $21,23 \mathrm{a}$ & $r^{2} 59,37 \% *$ \\
\hline
\end{tabular}

(1) Médias seguidas de letras iguais nas colunas, para a mesma variedade, não diferem entre si, a $5 \%$ de probabilidade, pelo teste de Scott Knott; * Regressão linear significativa: pr > t inferior a 0,05.

As variedades RB867515, SP79-1011, SP813250 e IAC91-5155 foram indiferentes às doses de fósforo corretivas, e possivelmente a dose de fósforo utilizada no sulco de plantio ( $165 \mathrm{~kg} \mathrm{ha}^{-1}$ de $\left.\mathrm{P}_{2} \mathrm{O}_{5}\right)$ e a menor em adubação corretiva $\left(150 \mathrm{~kg} \mathrm{ha}^{-1}\right)$ foram suficientes para suprir a demanda de $\mathrm{P}_{2} \mathrm{O}_{5}$ destas variedades, para acúmulo de sacarose, no primeiro e segundo ciclos. Korndörfer et al. (1998) afirmam que, para solos distróficos do Cerrado, a dose de $120 \mathrm{~kg}$ ha $^{-1}$ de $\mathrm{P}_{2} \mathrm{O}_{5}$ é a que possibilita maior retorno econômico, considerando a produção acumulada de cana-planta e primeira soca. Souza \& Korndörfer (2011), trabalhando com as variedades SP71-1406 e RB867515, não observaram efeito de fontes e de doses de fósforo na produtividade de colmos e industrial.

As variedades RB855035, SP81-1431 e RB835486 apresentaram comportamentos distintos para as características avaliadas. A RB855035 para Brix\% e a ATR $\mathrm{kg} \mathrm{t}^{-1}$ cana não apresentaram respostas significativas para as variáveis doses e épocas de corte; já para a Pol\% caldo e Fibra\%, a segunda época e a menor dose de fósforo foram as que proporcionaram melhor resposta. $\mathrm{Na}$ variedade SP81-1431, o Brix\% foi maior na última época com a menor dose de fósforo. Já a fibra aumentou com a maior dose, na última época de corte, isso pode ter influenciado o menor ATR para esta época, já que seu cálculo leva em consideração o Pol\% cana, e quanto mais elevada a porcentagem de fibra contida na cana-de-açúcar, menor é o valor do ATR (CONSECANA, 2006).

A variedade RB835486 apresentou melhores resultados na primeira época, com a adubação corretiva de $300 \mathrm{~kg}^{-1}$ de $\mathrm{P}_{2} \mathrm{O}_{5}$ para as características Brix\%, Pol\% caldo e ATR kg t-1 cana, evidenciando ser uma variedade responsiva à adubação corretiva com fósforo para colher em início de safra. O fato de o fósforo ser absorvido pelas raízes, principalmente por difusão, e esta tem correlação direta com a umidade do solo e as doses de fósforo (Costa et al., 2006), as melhores respostas ocorreram na primeira época (maio), quando ainda havia umidade no solo. 
Tabela 6 - Característica Pol\% caldo, na primeira soqueira, de dez variedades de cana-de-açúcar cultivadas sob duas doses de $\mathrm{P}_{2} \mathrm{O}_{5}$ em fosfatagem corretiva e com quatro épocas de corte. Characteristic Pol\% juice, first ratoon of ten varieties of sugarcane, grown under two rates of superphosphate, harvested in four different dates.

\begin{tabular}{|c|c|c|c|c|c|c|}
\hline \multirow{2}{*}{$\begin{array}{c}\text { Dose } \\
\left(\mathrm{kg} \mathrm{ha}^{-1}\right)\end{array}$} & \multirow{2}{*}{ Variedade } & \multicolumn{4}{|c|}{ (1)Épocas de corte } & \multirow{2}{*}{$\begin{array}{c}\text { Regressão } \\
\text { Época }\end{array}$} \\
\hline & & Maio & Junho & Julho & Agosto & \\
\hline 150 & \multirow{2}{*}{ SP83-2847 } & $13,43 \mathrm{a}$ & $16,07 \mathrm{a}$ & $17,77 \mathrm{a}$ & $19,20 \mathrm{a}$ & $r^{2} 97,93 \% *$ \\
\hline 300 & & $14,13 \mathrm{a}$ & $16,53 \mathrm{a}$ & $16,00 \mathrm{~b}$ & $19,63 \mathrm{a}$ & $r^{2} 81,46 \% *$ \\
\hline 150 & \multirow{2}{*}{ RB72454 } & $14,23 a$ & $17,00 \mathrm{a}$ & $18,13 a$ & $19,17 \mathrm{a}$ & $r^{2} 93,59 \% *$ \\
\hline 300 & & $15,17 \mathrm{a}$ & $16,00 \mathrm{a}$ & $16,37 \mathrm{~b}$ & $18,83 a$ & $r^{2} 86,64 \%{ }^{*}$ \\
\hline 150 & \multirow{2}{*}{ RB867515 } & $14,10 a$ & $16,13 \mathrm{a}$ & $18,03 a$ & $19,10 \mathrm{a}$ & $r^{2} 98,22 \% *$ \\
\hline 300 & & $14,93 \mathrm{a}$ & $16,37 \mathrm{a}$ & $17,60 \mathrm{a}$ & $19,17 \mathrm{a}$ & $r^{2} 99,81 \% *$ \\
\hline 150 & \multirow{2}{*}{ IACSP93-6006 } & $14,27 \mathrm{a}$ & $15,47 \mathrm{a}$ & $18,83 \mathrm{a}$ & $17,53 \mathrm{~b}$ & $r^{2} 68,98 \% *$ \\
\hline 300 & & $14,27 \mathrm{a}$ & $15,50 \mathrm{a}$ & $16,70 \mathrm{~b}$ & $19,23 \mathrm{a}$ & $r^{2} 96,17 \%$ * \\
\hline 150 & \multirow{2}{*}{ SP79-1011 } & $15,23 \mathrm{a}$ & $16,70 \mathrm{a}$ & $18,93 \mathrm{a}$ & $18,63 \mathrm{a}$ & $r^{2} 85,37 \% *$ \\
\hline 300 & & $14,93 \mathrm{a}$ & $16,37 \mathrm{a}$ & $17,83 \mathrm{a}$ & $19,27 \mathrm{a}$ & $r^{2} 100,0 \% *$ \\
\hline 150 & \multirow{2}{*}{ SP81-3250 } & $15,53 \mathrm{a}$ & $17,17 \mathrm{a}$ & $18,23 a$ & $19,30 \mathrm{a}$ & $r^{2} 98,76 \% *$ \\
\hline 300 & & $14,97 \mathrm{a}$ & $16,07 \mathrm{a}$ & $18,27 \mathrm{a}$ & $19,00 \mathrm{a}$ & $r^{2} 96,57 \% *$ \\
\hline 150 & \multirow{2}{*}{ IAC91-5155 } & $15,10 \mathrm{a}$ & $16,70 \mathrm{a}$ & $19,03 \mathrm{a}$ & $19,30 \mathrm{a}$ & $r^{2} 93,02 \% *$ \\
\hline 300 & & $16,67 \mathrm{a}$ & $17,33 \mathrm{a}$ & $18,30 a$ & $19,07 \mathrm{a}$ & $r^{2} 96,67 \% *$ \\
\hline 150 & \multirow{2}{*}{ RB855035 } & $14,50 \mathrm{a}$ & $16,90 \mathrm{a}$ & $17,73 \mathrm{a}$ & $19,87 \mathrm{a}$ & $r^{2} 97,56 \% *$ \\
\hline 300 & & $15,03 \mathrm{a}$ & $15,23 \mathrm{~b}$ & $18,10 a$ & $20,40 a$ & $r^{2} 91,71 \% *$ \\
\hline 150 & \multirow{2}{*}{ SP84-1431 } & $15,10 a$ & $18,10 \mathrm{a}$ & $18,23 a$ & $20,00 \mathrm{a}$ & $r^{2} 88,76 \%{ }^{*}$ \\
\hline 300 & & $15,93 a$ & $16,70 \mathrm{~b}$ & $18,60 \mathrm{a}$ & $18,77 \mathrm{a}$ & $r^{2} 91,52 \% *$ \\
\hline 150 & \multirow{2}{*}{ RB835486 } & $15,20 \mathrm{~b}$ & $16,83 \mathrm{a}$ & $20,03 \mathrm{a}$ & $19,60 \mathrm{a}$ & $r^{2} 84,75 \%$ * \\
\hline 300 & & $17,23 \mathrm{a}$ & $17,37 \mathrm{a}$ & $19,77 \mathrm{a}$ & $17,70 \mathrm{~b}$ & ns \\
\hline
\end{tabular}

(1) Médias seguidas de letras iguais nas colunas, para a mesma variedade, não diferem entre si, a $5 \%$ de probabilidade, pelo teste de Scott Knott; * regressão linear significativo pr > t inferior a 0,05; ns - não significativo.

Tabela 7 - Característica Fibra\%, na primeira soqueira, de dez variedades de cana-de-açúcar cultivadas sob duas doses de $\mathrm{P}_{2} \mathrm{O}_{5}$ em fosfatagem corretiva e com quatro épocas de corte. Characteristic Fiber\%, first ratoon of ten varieties of sugarcane, grown under two rates of superphosphate, harvested in four different dates.

\begin{tabular}{|c|c|c|c|c|c|c|}
\hline \multirow{2}{*}{$\begin{array}{c}\text { Dose } \\
\left(\mathrm{kg} \mathrm{ha}^{-1}\right)\end{array}$} & \multirow{2}{*}{ Variedade } & \multicolumn{4}{|c|}{ (1)Épocas de corte } & \multirow[t]{2}{*}{ Regressão } \\
\hline & & Maio & Junho & Julho & Agosto & \\
\hline 150 & \multirow{2}{*}{ SP83-2847 } & $12,83 a$ & $13,47 \mathrm{a}$ & $13,57 \mathrm{a}$ & $13,23 \mathrm{a}$ & ns \\
\hline 300 & & $11,77 \mathrm{a}$ & $13,50 \mathrm{a}$ & $13,23 \mathrm{a}$ & $12,30 \mathrm{a}$ & $r^{2} 95,45 \%$ ** \\
\hline 150 & \multirow{2}{*}{ RB72454 } & $10,90 \mathrm{a}$ & $09,87 \mathrm{a}$ & $11,54 \mathrm{a}$ & $11,83 \mathrm{a}$ & $r^{2} 43,97 \% *$ \\
\hline 300 & & $10,50 \mathrm{a}$ & $10,17 \mathrm{a}$ & $11,30 \mathrm{a}$ & $12,03 \mathrm{a}$ & $r^{2} 78,18 \% *$ \\
\hline 150 & \multirow{2}{*}{ RB867515 } & $11,27 \mathrm{a}$ & $11,27 \mathrm{a}$ & $12,67 \mathrm{a}$ & $12,90 \mathrm{a}$ & $r^{2} 85,26 \%{ }^{*}$ \\
\hline 300 & & $11,33 \mathrm{a}$ & $11,50 \mathrm{a}$ & $11,90 \mathrm{a}$ & $12,00 \mathrm{a}$ & ns \\
\hline 150 & \multirow{2}{*}{ IACSP93-6006 } & $10,63 \mathrm{a}$ & $10,70 a$ & $11,70 \mathrm{a}$ & $11,10 \mathrm{a}$ & ns \\
\hline 300 & & $10,37 \mathrm{a}$ & $11,20 \mathrm{a}$ & $11,07 \mathrm{a}$ & $11,70 \mathrm{a}$ & $r^{2} 82,35 \% *$ \\
\hline 150 & \multirow{2}{*}{ SP79-1011 } & $11,63 \mathrm{a}$ & $10,93 \mathrm{~b}$ & $12,00 \mathrm{a}$ & $13,27 \mathrm{a}$ & $r^{2} 62,03 \% \%^{*}$ \\
\hline 300 & & $10,73 \mathrm{a}$ & $12,17 \mathrm{a}$ & $12,23 \mathrm{a}$ & $12,80 \mathrm{a}$ & $r^{2} 84,43 \%{ }^{*}$ \\
\hline 150 & \multirow{2}{*}{ SP81-3250 } & $11,80 \mathrm{a}$ & $11,30 \mathrm{a}$ & $12,13 \mathrm{a}$ & $12,77 \mathrm{a}$ & $r^{2} 61,37 \% *$ \\
\hline 300 & & $10,87 \mathrm{a}$ & $11,47 \mathrm{a}$ & $11,60 \mathrm{a}$ & $12,43 \mathrm{a}$ & $r^{2} 93,47 \%$ \\
\hline 150 & \multirow{2}{*}{ IAC91-5155 } & $11,60 \mathrm{a}$ & $11,37 \mathrm{a}$ & $12,13 \mathrm{a}$ & $12,37 \mathrm{a}$ & ns \\
\hline 300 & & $11,63 \mathrm{a}$ & $11,13 a$ & $11,83 a$ & $12,43 \mathrm{a}$ & ns \\
\hline 150 & \multirow{2}{*}{ RB855035 } & $11,60 \mathrm{a}$ & $12,40 \mathrm{a}$ & $12,90 \mathrm{a}$ & $13,27 \mathrm{a}$ & $r^{2} 96,90 \% *$ \\
\hline 300 & & $11,30 \mathrm{a}$ & $10,80 \mathrm{~b}$ & $12,43 \mathrm{a}$ & $12,60 \mathrm{a}$ & $r^{2} 66,85 \% *$ \\
\hline 150 & \multirow{2}{*}{ SP84-1431 } & $11,17 \mathrm{a}$ & $10,93 a$ & $11,90 \mathrm{a}$ & $12,20 \mathrm{~b}$ & $r^{2} 77,12 \% *$ \\
\hline 300 & & $11,23 a$ & $11,23 a$ & $11,33 \mathrm{a}$ & $13,50 \mathrm{a}$ & $r^{2} 63,53 \% *$ \\
\hline 150 & \multirow{2}{*}{ RB835486 } & $11,07 \mathrm{a}$ & $10,97 b$ & $12,20 \mathrm{a}$ & $13,27 \mathrm{a}$ & $r^{2} 87,14 \% *$ \\
\hline 300 & & 11,50 a & $12,33 \mathrm{a}$ & $11,40 \mathrm{a}$ & $11,57 \mathrm{~b}$ & ns \\
\hline
\end{tabular}

(1) Médias seguidas de letras iguais nas colunas, para a mesma variedade, não diferem entre si, a $5 \%$ de probabilidade, pelo teste de Scott Knott; * Regressão linear significativa: pr > t inferior a 0,05; **regressão quadrática significativa: pr > t inferior a 0,05; ns - não significativo. 
Tabela 8 - ATR $\mathrm{kg} \mathrm{t}^{-1}$ cana, na primeira soqueira, de dez variedades de cana-de-açúcar cultivadas sob duas doses de $\mathrm{P}_{2} \mathrm{O}_{5}$ em fosfatagem corretiva e com quatro épocas de corte. ATR (recoverable total Sugar expressed by $\mathrm{kg} \mathrm{t}^{1}$ of stalk), first ratoon of ten varieties of sugarcane, grown under two rates of superphosphate, harvested in four different dates.

\begin{tabular}{|c|c|c|c|c|c|c|}
\hline \multirow{2}{*}{$\begin{array}{c}\text { Dose } \\
\left(\mathrm{kg} \mathrm{ha}^{-1}\right)\end{array}$} & \multirow{2}{*}{ Variedade } & \multicolumn{4}{|c|}{ (1)Épocas de corte } & \multirow{2}{*}{$\begin{array}{c}\text { Regressão } \\
\text { Epoca }\end{array}$} \\
\hline & & Maio & Junho & Julho & Agosto & \\
\hline 150 & \multirow{2}{*}{ SP83-2847 } & $114,83 \mathrm{a}$ & $131,33 \mathrm{a}$ & $143,33 \mathrm{a}$ & $156,20 \mathrm{a}$ & $r^{2} 99,49 \%{ }^{*}$ \\
\hline 300 & & $121,80 a$ & $134,47 \mathrm{a}$ & $132,10 \mathrm{~b}$ & $162,73 \mathrm{a}$ & $r^{2} 78,72 \%{ }^{*}$ \\
\hline 150 & \multirow{2}{*}{ RB72454 } & $124,40 a$ & $147,03 \mathrm{a}$ & $151,90 \mathrm{a}$ & $160,23 \mathrm{a}$ & $r^{2} 89,55 \% *$ \\
\hline 300 & & $132,00 \mathrm{a}$ & $139,03 \mathrm{a}$ & $139,57 \mathrm{~b}$ & $158,13 \mathrm{a}$ & $r^{2} 83,10 \% *$ \\
\hline 150 & \multirow{2}{*}{ RB867515 } & $122,60 \mathrm{a}$ & $137,23 \mathrm{a}$ & $148,37 \mathrm{a}$ & $156,83 \mathrm{a}$ & $r^{2} 98,55 \%{ }^{*}$ \\
\hline 300 & & $128,40 \mathrm{a}$ & $138,57 \mathrm{a}$ & $147,20 \mathrm{a}$ & $160,27 \mathrm{a}$ & $r^{2} 99,29 \% *$ \\
\hline 150 & \multirow{2}{*}{ IACSP93-6006 } & $125,13 \mathrm{a}$ & $130,00 \mathrm{a}$ & $157,03 \mathrm{a}$ & $149,47 b$ & $r^{2} 71,47 \%$ * \\
\hline 300 & & $126,20 \mathrm{a}$ & $132,83 \mathrm{a}$ & $142,80 \mathrm{~b}$ & $161,40 \mathrm{a}$ & $r^{2} 94,72 \% *$ \\
\hline 150 & \multirow{2}{*}{ SP79-1011 } & $130,50 a$ & $142,40 \mathrm{a}$ & $157,23 \mathrm{a}$ & $152,63 \mathrm{a}$ & $r^{2} 78,00 \%{ }^{*}$ \\
\hline 300 & & $129,87 a$ & $137,33 \mathrm{a}$ & $148,23 \mathrm{a}$ & $158,37 \mathrm{a}$ & $r^{2} 99,43 \% *$ \\
\hline 150 & \multirow{2}{*}{ SP81-3250 } & $132,50 a$ & $145,20 \mathrm{a}$ & $151,40 \mathrm{a}$ & $158,80 \mathrm{a}$ & $r^{2} 97,32 \%{ }^{*}$ \\
\hline 300 & & $130,20 a$ & $136,90 \mathrm{a}$ & $153,97 \mathrm{a}$ & $158,40 \mathrm{a}$ & $r^{2} 94,91 \% *$ \\
\hline 150 & \multirow{2}{*}{ IAC91-5155 } & $129,17 \mathrm{a}$ & $141,17 \mathrm{a}$ & $157,03 \mathrm{a}$ & $159,47 \mathrm{a}$ & $r^{2} 93,77 \% *$ \\
\hline 300 & & $133,20 \mathrm{a}$ & $147,03 \mathrm{a}$ & $152,07 \mathrm{a}$ & $157,70 \mathrm{a}$ & $r^{2} 93,56 \% *$ \\
\hline 150 & \multirow{2}{*}{ RB855035 } & $125,80 \mathrm{a}$ & $140,23 a$ & $153,30 \mathrm{a}$ & $161,53 \mathrm{a}$ & $r^{2} 98,61 \%{ }^{*}$ \\
\hline 300 & & $129,87 a$ & $131,93 a$ & $149,77 \mathrm{a}$ & $167,73 \mathrm{a}$ & $r^{2} 91,97 \%{ }^{*}$ \\
\hline 150 & \multirow{2}{*}{ SP84-1431 } & $131,07 \mathrm{a}$ & $153,73 a$ & $152,33 \mathrm{a}$ & $165,83 \mathrm{a}$ & $r^{2} 84,53 \% *$ \\
\hline 300 & & $136,37 \mathrm{a}$ & $142,60 \mathrm{~b}$ & $156,80 \mathrm{a}$ & $152,60 \mathrm{~b}$ & $r^{2} 75,84 \%$ * \\
\hline 150 & \multirow{2}{*}{ RB835486 } & $131,63 \mathrm{~b}$ & $143,47 \mathrm{a}$ & $165,10 \mathrm{a}$ & $159,40 \mathrm{a}$ & $r^{2} 79,06 \% *$ \\
\hline 300 & & $145,47 \mathrm{a}$ & $144,57 \mathrm{a}$ & $165,23 \mathrm{a}$ & $149,77 \mathrm{a}$ & $r^{2} 20,42 \%{ }^{*}$ \\
\hline
\end{tabular}

(1) Médias seguidas de letras iguais nas colunas, para a mesma variedade, não diferem entre si, a $5 \%$ de probabilidade, pelo teste de Scott Knott; * Regressão linear significativa: pr > t inferior a 0,05.

Separando-se as variedades por ciclo de maturação, têm-se três grupos: as de maturação precoce SP84-1431, RB855035, RB865486 e IAC915155; as de maturação média SP81-3250, SP79-1011 e IACSP93-6006, e as de maturação tardia RB867515, SP83-2847 e RB72454 (COPERSUCAR, 1999; IAC, 2000; RIDESA, 2008). Na média de Pol\% caldo das variedades precoces e tardias, respectivamente, para a primeira época de corte (maio), verifi- cou-se incremento de 1,0 e $0,8 \%$ na Pol\% caldo na maior dose de fósforo, enquanto as variedades médias apresentaram menores valores de Pol\% caldo na maior dose de fósforo, e voltaram a acumular sacarose no último corte, realizado em agosto (Figuras 3; 4 e 5). Tais resultados mostram que, no geral, as variedades precoces e tardias tiveram comportamentos semelhantes e bem distintos dos comportamentos apresentados pelas variedades consideradas médias.

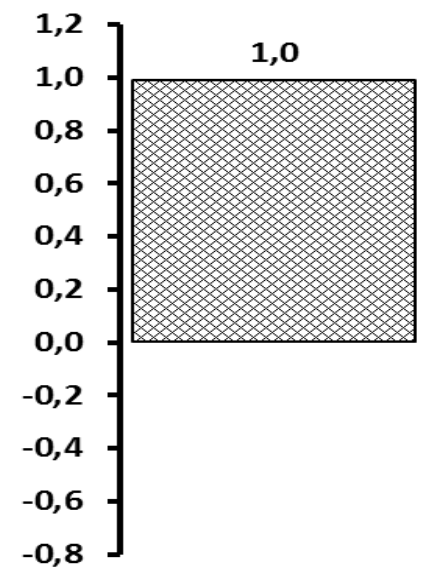

MAIO

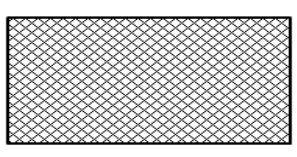

$$
-0,5
$$

JUNHO

\section{GRUPO PRECOCES}

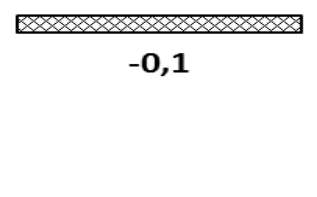

JULHO

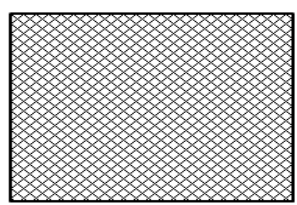

$-0,7$
AGOSTO

Figura 3 - Diferenças de Pol\% caldo das variedades precoces, entre as doses de 150 e $300 \mathrm{~kg} \mathrm{ha}^{-1}$ de $\mathrm{P}_{2} \mathrm{O}_{5}$ em adubação corretiva. Differences in Pol\% juice of early maturing varieties, between rates of 150 and $300 \mathrm{~kg} \mathrm{ha}^{-1}$ of $\mathrm{P}_{2} \mathrm{O}_{5}$ in corrective fertilization. 
Os resultados das variedades precoces e tardias obtidos no mês de maio concordam com Albuquerque et al. (1979), porém contrariam resultados de Penatti (1991), Korndörfer (1990) e Pereira et al. (1995). Deve-se, no entanto, enfatizar que os trabalhos citados foram realizados com outras variedades, com diferentes níveis de exigências climáticas e nutricionais, além de a adubação fosfatada ter sido realizada no sulco de plantio e apenas em um corte.

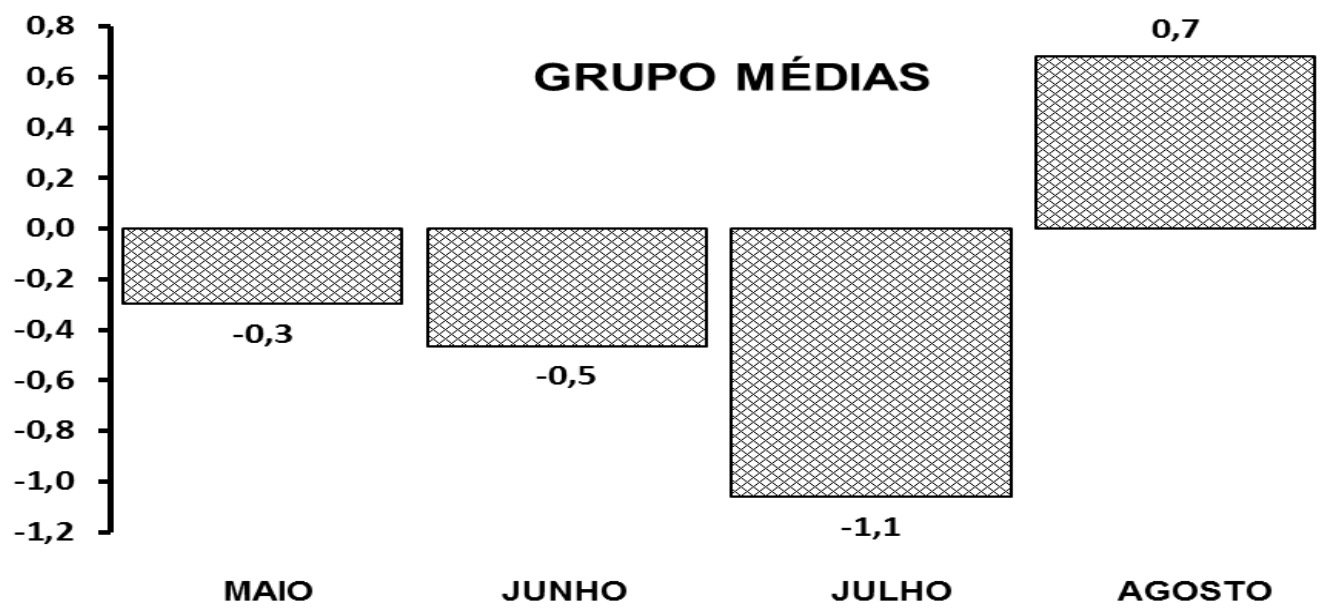

Figura 4 - Diferenças de Pol\% caldo das variedades médias, entre as doses de 150 e $300 \mathrm{~kg} \mathrm{ha}^{-1}$ de $\mathrm{P}_{2} \mathrm{O}_{5}$ em adubação corretiva. Differences in Pol\% juice of middle maturing varieties, between rates of 150 and $300 \mathrm{~kg} \mathrm{ha}^{-1}$ of $\mathrm{P}_{2} \mathrm{O}_{5}$ in corrective fertilization.

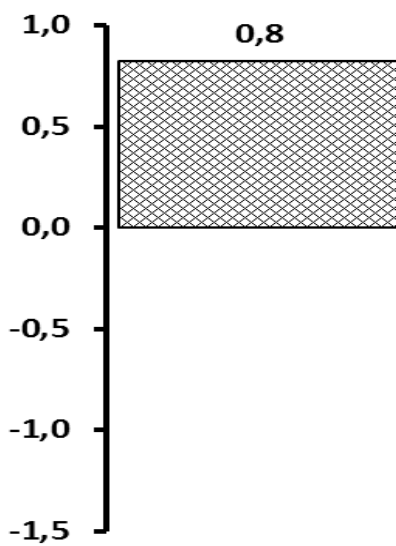

MAIO

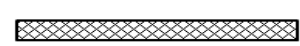

$-0,1$

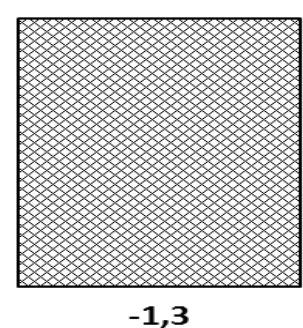

JULHO $\mathbf{0 , 0}$

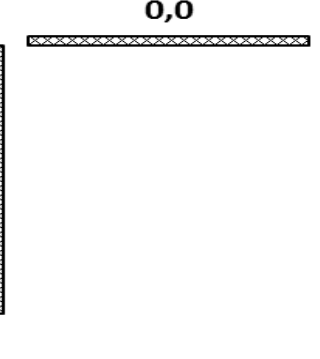

AGOSTO

Figura 5 - Diferenças de Pol\% caldo das variedades tardias, entre as doses de 150 e $300 \mathrm{~kg} \mathrm{ha}^{-1} \mathrm{de}^{\mathrm{P}_{2} \mathrm{O}_{5}}$ em adubação corretiva. Differences in Pol\% juice of of late maturing varieties, between rates of 150 and 300 kg ha-1 of $\mathrm{P}_{2} \mathrm{O}_{5}$ in corrective fertilization.

Analisando os resultados de diversas safras de cana-de-açúcar no Brasil (MAPA, 2013b), verificase que o teor de sacarose evoluiu muito pouco, enquanto no mesmo período ocorreram ganhos significativos na produtividade de colmos. Deste modo, os resultados deste trabalho mostram que o manejo da adubação fosfatada nestes ambientes restritivos pode ser uma estratégia para se aumentar o acúmulo de sacarose. Cabe ainda destacar que estes resultados expressam efeito residual da adubação corretiva apenas no segundo ciclo, o que realça, ainda mais, a necessidade de novos trabalhos nesta área, e investigações mais detalhadas, principalmente em função dos elevados preços dos fertilizantes.

\section{Conclusões}

As variedades respondem de modo diferente à adubação fosfatada corretiva, além de que as variedades precoces e as tardias colhidas no mês de maio acumulam mais Pol\% caldo na dose de $300 \mathrm{~kg} \mathrm{ha}^{-1}$ de $\mathrm{P}_{2} \mathrm{O}_{5}$.

A adubação fosfatada corretiva é uma boa opção técnica para manejar a qualidade da matéria-prima e deve ser considerada no planejamento do manejo varietal. 


\section{Referências}

Albuquerque GAL, Marinho ML, Araujo Filho LI (1979) Competição de fontes de fósforo em cana-de-açúcar. STAB 2:319-322.

Alexander AG (1973) A comprehensive study of the Saccharum source-to-sink system. Sugarcane Physiology. 752p.

Cantarella H, Rossetto R, Landel MGA, Bidóia MAP, Vasconcelos ACM (2002) Mistura em diferentes proporções de fosfato natural reativo e fosfato solúvel em água para a cana-de-açúcar. Stab 8:218-224.

CONAB (2014) Cana-de-açúcar, quarto levantamento abril/2014, Acompanhamento de safra brasileira. Disponível em: <http://www.conab.gov.br/OlalaCMS/uploads/arquivos/ 14_04_10_09_00_57_boletim_cana_portugues__4o_lev_-_13.pdf> (Acesso em 19 maio 2014).

CONSECANA (2006) Manual de instruções. CONSECANA-SP 5:116p.

COPERSUCAR (1999) $7^{\text {a }}$ Geração de variedades de cana-de-açúcar. COPERSUCAR. 32p.

Costa JPV, Barros NF, Albuquerque AW, Moura Filho G, Santos JR (2006) Fluxo difusivo de fósforo em função de doses e da umidade do solo. Revista brasileira de engenharia agrícola e ambiental 10:4.828-835.

Elamin EA, Eltilib MA, Elnasikh MH, Ibrahim SH, Elsheikh MA, Babiker EE (2007) The influence of phosphorus and potassium fertilization on the quality of sugar of two sugarcane varieties grown on three soil series of Sudan. Journal of Applied Sciences 7:1.23452350.

EMBRAPA (2006) Sistema brasileiro de classificação de solos. Embrapa Informação Tecnológica. 306p.

Ferreira DF (2000) Análises estatísticas por meio do Sisvar para Windows versão 4.0. UFSCar 45:255-258.

Figueiredo Filho CP (2002) Avaliação da adubação fosfatada da cana-de-açúcar com hiperfosfato natural reativo. STAB 8:259-263.

HORII JA (2004) Qualidade da matéria-prima na visão agrícola. Visão Agrícola 1:91-93.

IAC (2000) Novas variedades IAC de cana-de-açúcar. Disponível em:

http://www.iac.sp.gov.br/publicacoes/agronomico/pdf/5 223_p22_cv_cana.pdf> (Acesso em 19 jun 2014).

Korndörfer GH (1990) Fertilizantes fosfatados sólidos e fluidos na cana-de-açúcar. Escola Superior de Agricultura "Luiz de Queiroz" Universidade de São Paulo (Tese de Doutorado).
Korndörfer GH, Faria RJ, Martins M (1998) Efeito do fósforo na produção de cana-de-ano e cana-soca cultivada em solo de cerrado. Pesquisa Agropecuária Brasileira 33:10.1667-1673.

Korndörfer GH (2004) Fósforo na cultura da cana-deaçúcar. Associação brasileira para pesquisa da Potassa e do fosfato 2:291-305.

Korndörfer GH, Melo SP (2009) Fontes de fósforo (fluida ou sólida) na produtividade agrícola e industrial da cana-de-açúcar. Ciência e Agrotecnologia 33:92-97.

Lima AFP, Casagrande AA, Barbosa JC, Neme LH (1990) Comportamento de variedades de cana-deaçúcar, no município de Dumont-SP, com a ocorrência de déficit hídrico no período de desenvolvimento. STAB 9:12.31-38.

Lima SAA, Silva IF, Santiago RD, Silva Neto LR, Souza C, Cavalcante FS (2006) Influência da adubação mineral sobre três cultivares de cana-de-açúcar na microrregião de Guarabira na Paraíba. Agropecuária Técnica 27:1.92-99.

Malavolta E (2006) Manual de nutrição mineral de plantas. Ceres. 638p.

MAPA (2013a) Projeções do Agronegócio: Brasil 2012/2013 a 2022/2023. Disponível em: <http://www.agricultura.gov.br/arq_editor/projecoes\%20\%20versao\%20atualizada.pdf> (Acesso em 19 mai. 2014).

MAPA (2013b) Anuário estatístico de agroenergia 2012. Ministério da Agricultura, Pecuária e Abastecimento. 284p.

MAPA (2014) Cana-de-açúcar. Disponível em: <http://www.agricultura.gov.br/vegetal/culturas/canade-acucar> (Acesso em 19 mai. 2014).

Morelli JL, Nelli EJ, Baptistela JR, Demattê JLI (1991) Termofosfato na produtividade da cana-de-açúcar e nas propriedades químicas de um solo arenosos de baixa fertilidade. Revista Brasileira de Ciência do Solo 15:57-61.

Martins NGS (2004) Os fosfatos na cana-de-açúcar. Escola Superior de Agricultura "Luiz de Queiroz" Universidade de São Paulo (Dissertação de Mestrado).

Penatti, C (1991) Uso de Ácido Fosfórico ou Superfosfato Triplo como Fonte de Fósforo para a Cultura da Cana-de-Açúcar. Escola Superior de Agricultura "Luiz de Queiroz", Universidade de São Paulo (Dissertação de Mestrado).

Pereira, JF, Faria CMB, Morgano LB (1995) Efeito de níveis e do resíduo de fósforo sobre a produtividade de cana-de-açúcar em vertissolo. Pesquisa Agropecuária Brasileira 30:43-48. 
RIDESA (2008) Variedades RB. Disponível em: <http://pmgca.dbv.cca.ufscar.br/dow/VariedadesRB_2 008.pdf> (Acesso em 19 jun. 2014).

Rodella AA, Martins M (1988) Efeitos de fontes e formas de aplicação de fósforo na produtividade da cana-deaçúcar, em cana-planta. Álcool e Açúcar 45:8.26-30.

Rossetto R, Farhat M, Furlan R, Gil MA, Silva SF (2002) Eficiência agronômica do fosfato natural na cultura da cana-de-açúcar. STAB 21:276-282.

Rossetto R, Dias FLF (2005) Nutrição e adubação da cana-de-açúcar. Informações Agronômicas 110: 10p.

Santos DH, Silva MA, Tiritan CS, Foloni JSS, Echer FR (2011) Qualidade tecnológica da cana-de-açúcar sob adubação com torta de filtro enriquecida com fosfato solúvel. Revista Brasileira de Engenharia Agrícola e Ambiental 15: 443-449.
Sobral BWS, Braga DPV, Lahood ES, Keim P (1994) Phylogenetic analysis of chloroplast restriction enzyme site mutations in the Saccharinae Griseb. Theoretical and Applied Genetics 87: 843-853.

Sousa DMG, Lobato E (2004) Cerrado: correção do solo e adubação. Embrapa. 2ed. 416p.

Sousa DMG, Volksweiss SJ (1987) Efeito residual do superfosfato triplo em pó e em grânulos no solo. Revista Brasileira de Ciência do Solo 11:141-146.

Souza RTX, Korndörfer GH (2011) Efeito da aplicação de fertilizantes fosfatados na produtividade da canade-açúcar. Enciclopédia Biosfera 7:12.1.

Tomaz HVQ (2009) Fontes, doses e formas de aplicação de fósforo na cana-de-açúcar. Escola Superior de Agricultura Luiz de Queiroz, Universidade de São Paulo (Dissertação de Mestrado). 